\title{
On the derivation of soil surface roughness from multi parametric PolSAR data and its potential for hydrological modeling
}

\author{
P. Marzahn and R. Ludwig \\ Department of Geography, Ludwig-Maximilian University Munich, Germany \\ Received: 26 September 2008 - Published in Hydrol. Earth Syst. Sci. Discuss.: 28 November 2008 \\ Revised: 3 March 2009 - Accepted: 3 March 2009 - Published: 18 March 2009
}

\begin{abstract}
The potential of multi parametric polarimetric SAR (PolSAR) data for soil surface roughness estimation is investigated and its potential for hydrological modeling is evaluated. The study utilizes microwave backscatter collected from the DEMMIN test site in the North East of Germany during the AgriSAR 2006 campaign using fully polarimetric L-band E-SAR data. In addition to various measurements of soil physical properties, soil surface roughness was measured extensively using photogrammetric image matching techniques for ground truthing. The resulting micro-DSMs are analyzed to correlate a soil surface roughness index to three well established polarimetric roughness estimators. Good results are obtained for $R e_{[\rho R R L L]}$ vs. RMS Height for areas with a polarimetric alpha angel $\alpha<40^{\circ}$, which is thus used to produce multi temporal roughness data of the test site. The proposed roughness inversion scheme showed sufficiently accurate results (RMSE $=0.1$ ) to allow for a first order assessment of soil-hydrological parameters (soil porosity, void ratio), which are crucial for the initialization and operation of hydrological surface models. While uncertainties remain, the dependency of soil bulk density parameters from surface roughness can be shown and thus highlights the potential of the retrieval approach for hydrological model applications.
\end{abstract}

\section{Introduction}

At the boundary between the atmosphere and the pedosphere, soil surface roughness plays an important role in numerous physical processes related to water, energy and nutrient flux and exchange. This has been widely recognized in novel land surface modeling efforts. On cultivated soils, many stud-

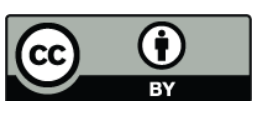

Correspondence to: P. Marzahn

(p.marzahn@iggf.geo.uni-

muenchen.de) ies have demonstrated that different roughness states influence runoff generation and formation due to soil sealing and crusting effects (Fohrer et al., 1999). Furthermore, processes like infiltration, evaporation, soil erosion by wind and water, lateral and vertical matter fluxes, as well as the growth and vitality of particular agricultural plants are all influenced by soil surface roughness states and the resulting changes in soil bulk density, respectively the soil void ratio in the upper few centimetres of the soil column (Farres, 1980; Helming, 1992; Le Bissionais et al., 1998; Fohrer et al., 1999; Cerdan et al., 2001; Darboux et al., 2002; Zeiger, 2007).

Changes in soil surface roughness conditions are related to agricultural practice or to precipitation and wind effects. While meteorological impacts cause a smoothing of the soil surface and an increase in bulk density, agricultural practice produces different roughness states depending on the applied tillage tool and strategy. Allmaras et al. (1966) defined two different roughness terms with regard to their geometrical appearance: orientated and random roughness. While orientated roughness is dependent on the tillage tool or general slope effects, the random roughness is caused by the fortuitous occurrence of peaks and depressions resulting from soil clods and organization of aggregates which cannot be addressed to orientated roughness (Allmaras et al., 1966). Römkens and Wang (1986) defined the random roughness alongside other scale dependent roughness types as the height deviations from a reference plain in the scale of $2-200 \mathrm{~mm}$.

For soil surface roughness characterization on small plots up to $16 \mathrm{~m}^{2}$, different roughness indices have been proposed and successfully utilized (Allmaras et al., 1966; Bertuzzi, 1990; Taconet and Ciarletti, 2007; Zeiger, 2007). However, the direct measurement of soil surface roughness on the field scale is not yet appropriately solved. This is leading to strong simplification and considerable uncertainty in the description of spatial soil surface roughness conditions in recent physically based runoff generation modeling efforts

Published by Copernicus Publications on behalf of the European Geosciences Union. 


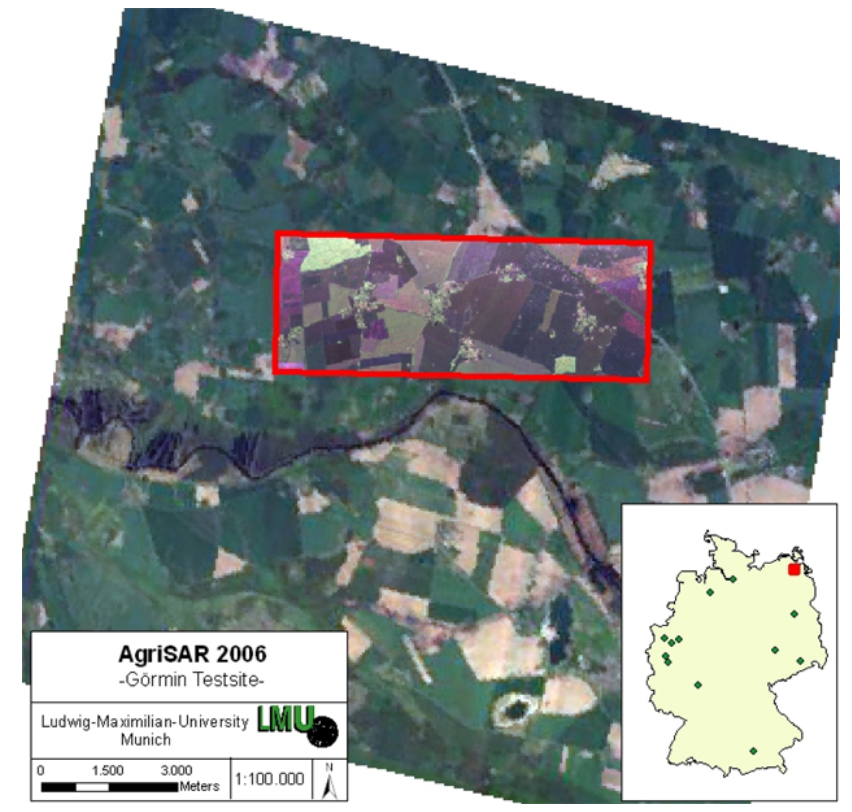

Fig. 1. Overview of DEMMIN-Görmin test site in the North East of Germany.

on the catchment scale. While expensive and labor intensive in-situ measurements are limited to small areas, remote sensing techniques are able to cover larger areas at relatively high frequency, which might offer the opportunity to measure dynamic soil surface characteristics on larger scales (Santanello et al., 2007; Loew and Mauser, 2008). In this study, the derivation of soil surface roughness information on field scale is conducted and evaluated from multi temporal airborne PolSAR data. To investigate the application potential in hydrological modeling, the deployment of multi temporal soil surface roughness maps for the retrieval of soil physical parameters, such as bulk density and void ratio, are presented as first results of a feasibility study.

\section{Methods and field data}

The study was performed in the frame of the ESA-founded campaign AgriSAR 2006, which was carried out from midApril to the end of July at the DEMMIN (Durable Environmental Multidisciplinary Monitoring Information Network) test site (Hajnsek et al., 2007). A major component of this study was to generate an image and ground data base on a weekly basis for the examination and validation of bio/geo-physical parameter retrievals and to simulate ESA's future Sentinel 1 and Sentinel 2 missions. Therefore, weekly E-SAR flights, operated by the German Aerospace Centre (DLR-HR), were accompanied by extensive in-situ measurements.

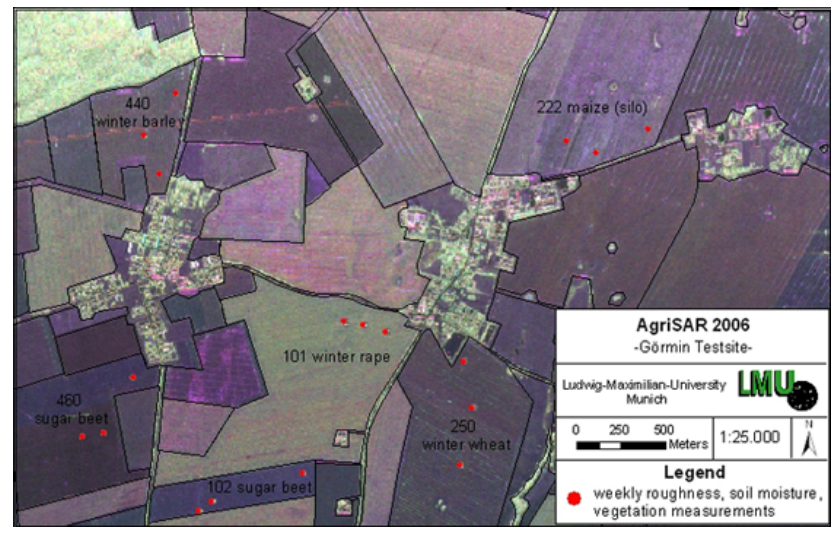

Fig. 2. Location of sample points within the Görmin test site during AgriSAR 2006.

\subsection{Test site}

DEMMIN is a consolidated test site in Mecklenburg-Western Pomerania in North East Germany, approximately $150 \mathrm{~km}$ north of Berlin (Fig. 1). The $3 \times 8 \mathrm{~km}^{2}$ test site is located in the young moraine area, characterized by smooth topography and intensive agricultural cultivation on high productive soils. The altitudinal range within the test site is about $60 \mathrm{~m}$ with its maximum in the north and a minimum in the southern part of the test site near the Peene river. Soil texture ranges from sandy loam to loamy sand. The main crop rotation is winter wheat, winter rape and winter barley. Additionally, maize and sugar beet is sown in spring for livestock feed. The mean field size is 225 ha. Due to very large fields and intensive cultivation, wind, water or tillage induced erosion patterns such as shortened soil columns can be observed within the fields.

18 sample points were chosen to represent soil conditions under the main crops in the test site during the campaign. Figure 2 shows the locations of the sample points. Most of the sampling points are situated in plain areas except for sample points (ESU) 102-1 (SB) and 222-2 (M) which are located in local sinks or in small drainage channels.

\subsection{In-field measurements}

\subsubsection{Roughness characterization}

For measuring soil surface roughness a photogrammetric approach was chosen due to its 3 dimensional output and highly accurate estimates. A further advantage for choosing a photogrammetric approach is its efficiency with regard to a decoupled acquisition and analysis compared to similar accurate acquisition setups such as laser devices (Rieke-Zapp and Nearing, 2005). To collect samples over a wide range of roughness states, soil surface roughness measurements were performed on 18 sample points (Fig. 2). Roughness conditions ranged from smooth and crusted surfaces to ploughed 


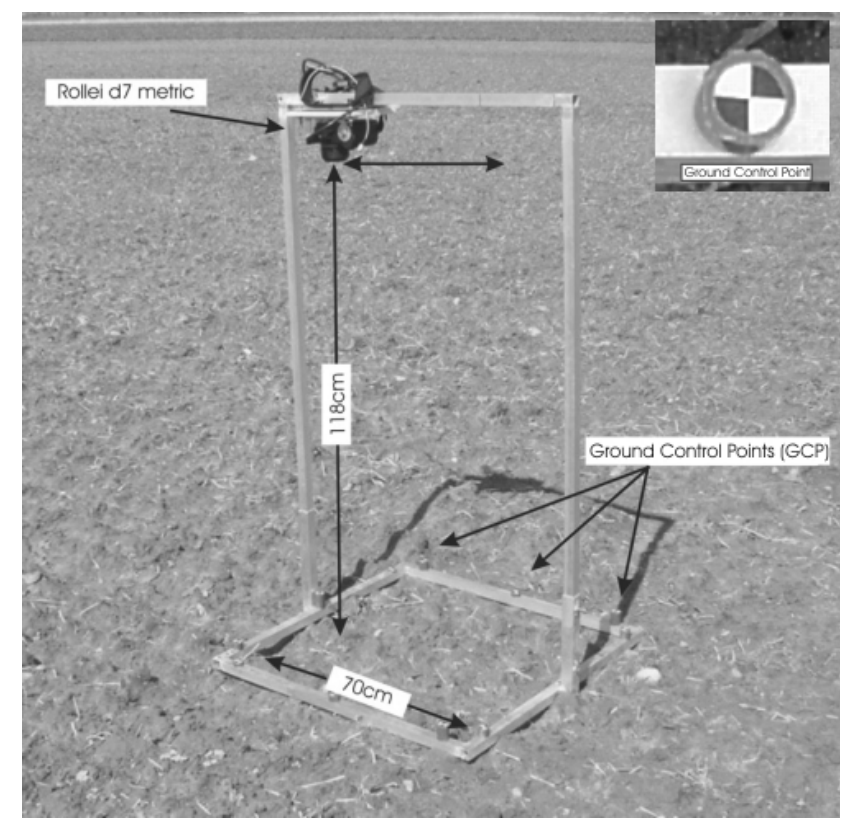

Fig. 3. Camera system for photogrammetric image acquisition (setup and signalized control point).

and harrowed fields. For sampling surface roughness on vegetated fields, plants were carefully cut off at the surface and completely removed from the areas covered by photogrammetric image acquisitions, without disturbing the soil surface.

For image acquisition, a Rollei d7 metric camera with known interior orientation was mounted on a tripod approximately $118 \mathrm{~cm}$ above the soil surface. The self-developed aluminum tripod (Fig. 3) accommodates 12 ground control points (GCP) whose three dimensional (xyz) coordinates were manually determined, as described by Lascelles et al. (2002), using a caliper rule with an accuracy of $1 / 10 \mathrm{~mm}$. The horizontal coverage of the sampling area is limited to $70 \times 70 \mathrm{~cm}^{2}$ (approx. $0.5 \mathrm{~m}^{2}$ ). The camera and tripod setup allows an image acquisition from $1180 \mathrm{~mm}$ above ground with a baseline of $480 \mathrm{~mm}$ resulting in a height-to-base ratio of 2.5 and an image overlap of approximately $65 \%$, which is appropriate for roughness measurements (Rieke-Zapp and Nearing, 2005; Linder, 2006). Thus, the image block consists of two images at which the acquired images have a spatial resolution of $0.54 \mathrm{~mm}$.

Digital Surface Models (DSM) were generated using Leica Photogrammetry Suite (LPS 9.0). Exterior orientation of the two images was established using the highly accurate GCPs and bundle block adjustment techniques. Therefore, additionally to the 12 known GCPs, tie-points were derived and their three dimensional coordinates were calculated respectively. Best results in bundle block adjustment were achieved by using an additional 12-parameter model (Ebner, 1976). For DSM generation, LPS uses image match-

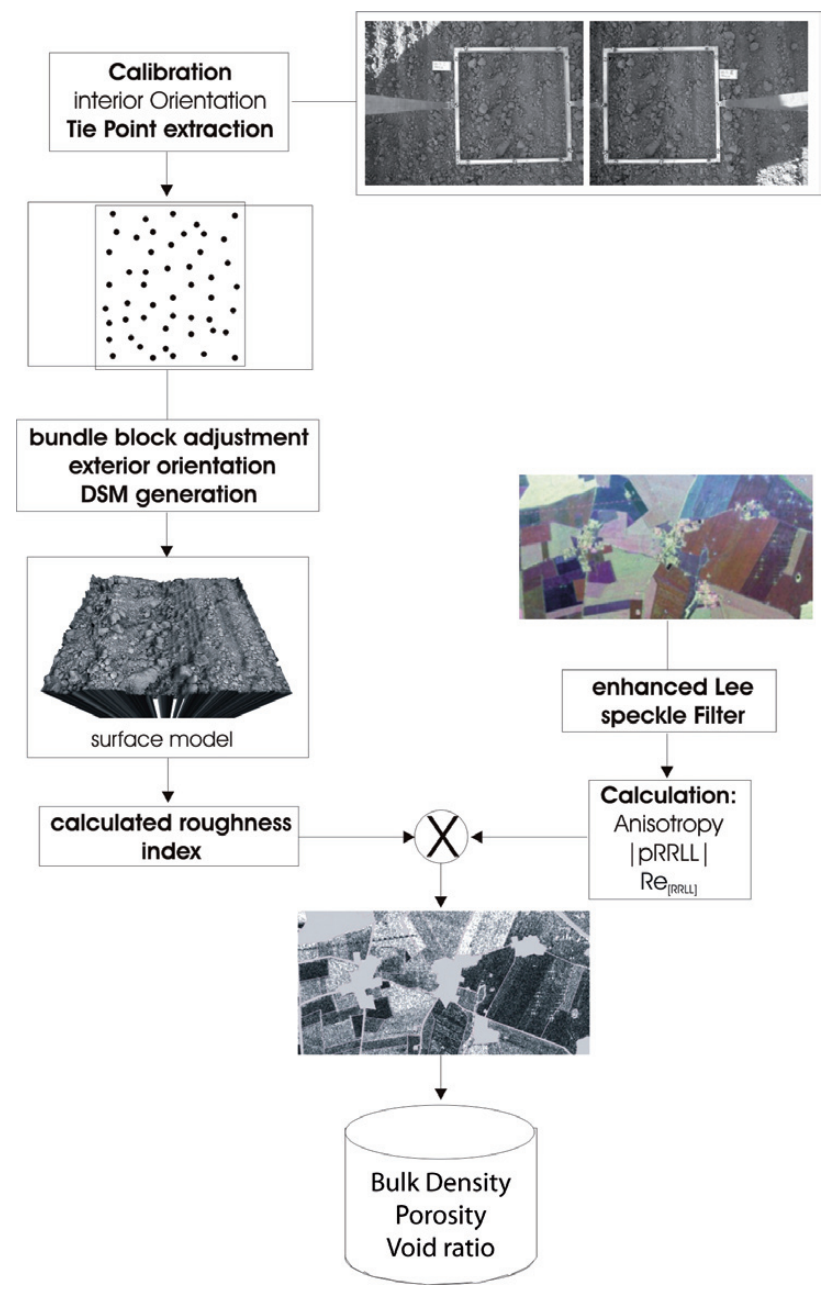

Fig. 4. Scheme of the roughness retrieval approach.

ing strategies which work in epipolar lines (LPS, 2006). For different roughness states, adjusted matching strategies have been developed, which only vary in the $\mathrm{x}$ direction and deliver a good fit to the known GCPs and the highly accurate tie-points. The minimum correlation coefficient for the matching process, calculated from a $11 \times 11$ kernel between the two images, was set to 0.65 , which is sufficient for epipolar line based matching algorithms (Stojic et al., 1998, Linder, 2006). In a final step, the generated DSMs were interpolated to a regular grid with a nominal resolution of $2 \mathrm{~mm}$. A low-pass filter using a $7 \times 7$ kernel was applied to remove outliers.

In order to quantify soil surface roughness as a function of soil geometrical properties, roughness indices can be calculated from the derived DSM using different statistical approaches. Allmaras et. al (1966) and Currence and Lovely (1970) propose different calculation procedures based on the standard deviation of height values with additional terms to remove general slope effects. Due to the tripod geometrics perpendicular to the surface, a superimposition of general 
slope effects can be excluded. Thus the calculation of the RMS Height can be simplified to:

$s=\sqrt{\frac{\sum_{i=1}^{n}\left(Z_{i}-\bar{Z}\right)^{2}}{1-n}}$

Where $s$ is the RMS Height in $(\mathrm{cm})$ and $Z$ is the height value in $(\mathrm{cm})$.

Some authors (Currence and Lovely, 1970; Römkens and Wang, 1986; Linden and Van Doren, 1986; Sommer, 1997) have criticized these roughness indices for not maintaining the spatial distribution of height measurements for physical interpretation. Still, the RMS Height is the common and generally preferred index to describe soil surface roughness conditions in radar remote sensing and is therefore applied in this study (Oh et al., 1992; Hajnsek et al., 2003; Loew et al., 2006).

In addition, to quantify the non isotropic behavior of the sampled surface, the RMS Height parallel and perpendicular to the tillage direction was calculated separately. The mean RMS Height parallel to the tillage direction is then defined as:

$\bar{s}_{x(y)}=\frac{\sum_{j=1}^{m} \sqrt{\frac{\sum_{i=1}^{n}\left(Z_{i(y)}-\bar{Z}_{y}\right)^{2}}{1-n}}}{m}$

While the average RMS Height perpendicular to the tillage direction is defined as:

$\bar{s}_{y(x)}=\frac{\sum_{j=1}^{m} \sqrt{\frac{\sum_{i=1}^{n}\left(Z_{i(x)}-\bar{Z}_{x}\right)^{2}}{1-n}}}{m}$

As a consequence, the ratio $\bar{s}_{x(y)} / \bar{s}_{y(x)}$ is a measure for the directionality of the surface roughness, where for a value of 1 the surface is an absolute isotropic scatter.

As roughness is a function of wavelength, its appearance changes with different wavelengths. Using lower frequencies, the illuminated targed appears much smoother than at higher frequencies. To compensate this effect, the RMS Height has to be scaled to the actual wavelength using the wavenumber $k$ within the following equation:

$k s=s \times k=s \times \frac{2 \pi}{\lambda}$

Where $k s$ is the RMS Height normalized to the wavenumber $k$ and $\lambda$ the wavelength (at the used L-band 23,054 cm).

As demonstrated by different authors (Davidson et al., 2000; Verhoest et al., 2007, 2008) roughness parameters often change with the length of profile over which they are estimated. Davidson et al. (2000) observed an increase in the RMS Height with an increasing profile length (1 and $10 \mathrm{~m}$ ) in range of $0.5 \mathrm{~cm}$ for rolled fields, $0.6 \mathrm{~cm}$ for harrowed and $1.2 \mathrm{~cm}$ for ploughed fields. While those investigations are mainly focused on roughness data obtained by profile lasers or mesh boards, the effect of larger sample coverage on the RMS Height using 3 d information is subject to only few studies. In their extensive work, Taconet and Ciarletti (2007) investigated the accuracy of different roughness estimators with changing sampling coverage. From an initial DSM with $0.77 \mathrm{~m}$ width and $2.95 \mathrm{~m}$ length they calculated different sub DSMs ranging from $0.4 \mathrm{~m}$ to $2.95 \mathrm{~m}$ length and a width of $0.77 \mathrm{~m}$ and compared those estimated roughness values with the true estimates. Within this study, the acquired sampling area results in an accuracy of $90 \%$ for representing the true roughness conditions for ploughed fields and $92.5 \%$ accuracy for seedbed structures (Taconet and Ciarletti 2007).

\subsubsection{Soil and vegetation parameters}

In addition to those above mentioned roughness measurements, a broad variety of focussed in-situ measurements was carried out simultaneous to E-SAR flights. The main sampling routine included soil physical characteristics (soil moisture, roughness, bulk density) as well as vegetation parameters (wet/dry biomass, vegetation cover, plant height, LAI, shoots per $\mathrm{m}^{2}$ ).

After photogrammetric image acquisition, soil samples were taken for moisture, bulk density and texture analysis. Soil moisture content was measured gravimetrically (oven drying at $105^{\circ} \mathrm{C}$ ) using $100 \mathrm{~cm}^{2}$ Kopecky rings, at depth of $0-5 \mathrm{~cm}$ and $5-10 \mathrm{~cm}$, with three repetitions each. From the known volume of the Kopecky rings volumetric soil moisture $\left(\right.$ Vol. \%) as well as bulk density $\left(\mathrm{g} / \mathrm{cm}^{3}\right)$ was calculated subsequently.

\subsection{Radar acquisitions and processing}

A total of 11 E-SAR flights were carried out on a weekly basis, recording imagery in $\mathrm{X}-, \mathrm{C}-$, and L-band with an incidence angle ranging from $25^{\circ}$ to $55^{\circ}$. The raw radar data was preprocessed radiometrically and geometrically at DLR-HR. The L-band radar data showed good quality with an absolute error of $-2 \mathrm{~dB}$ and a phase accuracy of $2^{\circ}$ (Scheiber et al., 2007).

Geocoded Single Look Complex (SLC) L-band data with a spatial resolution of $2 \times 2 \mathrm{~m}^{2}$ was chosen to retrieve roughness information. As shown by Thiel et al. (2001) it is feasible to use geocoded SLC E-SAR L-band data to perform polarimetric image analysis. Prior to further image analysis, the radar imagery was speckle filtered by applying a $7 \times 7$ window enhanced LEE-Filter (Lee et al., 1992), which corresponds to approximately 34 looks.

Cloude and Pottier (1996) developed a very useful decomposition theorem which is based on the eigenvalue and eigenvector decomposition of the coherency matrix $[\mathbf{T}]$. On base of the diagonalization of the $[\mathbf{T}]$ matrix, three important 
physical parameters arise. The first two parameters are derived from the eigenvalues $\lambda_{1}-\lambda_{3}$ and are namely the Entropy $H$ and the Anisotropy $A$ and give an overview about the amount of different scattering mechanisms within a resolution cell (Hellmann et al., 1999). The third parameter, the polarimetric alpha angle $\alpha$, is derived from the eigenvectors of the coherency matrix [T], were each eigenvector $\boldsymbol{e}_{\boldsymbol{i}}$ can be expressed in terms of five angles as shown in (5) (Cloude and Pottier 1997).

$\boldsymbol{e}_{\boldsymbol{i}}=\left[\begin{array}{c}\cos \alpha_{i} \exp \left(i \phi_{1 i}\right) \\ \sin \alpha_{i} \cos \beta_{i} \exp \left(i \phi_{2 i}\right) \\ \sin \alpha_{i} \sin \beta_{i} \exp \left(i \phi_{3 i}\right)\end{array}\right]$

The $\beta_{i}$ angles can be interpreted as the orientation angle containing information of the rotation of the eigenvector $\boldsymbol{e}_{\boldsymbol{i}}$ in the plane perpendicular to the scattering plane, while $\phi_{j i}$ giving information about the phase relations between the elements of $\boldsymbol{e}_{i}$. To obtain information about the mean scattering angle $\alpha$ Eq. (5) has to be transposed and the mean $\alpha$ angle can by calculated using the probabilities $p_{i}$ (Cloude and Pottier, 1996):

$\alpha=p_{1} \alpha_{1}+p_{2} \alpha_{2}+p_{3} \alpha_{3} \rightarrow p_{1}+p_{2}+p_{3}=1$

The polarimetric alpha angle ranges from $0^{\circ}$ to $90^{\circ}$. It can be used to represent and differentiate between a wide variety of scatter mechanisms (Cloude and Pottier, 1996, 1997). An alpha angle of $\alpha=0^{\circ}$ can be interpreted as surface scattering. With an increase in $\alpha$ the surface becomes anisotropic due to the presence of small plants or non isotropic tillage patterns. At an alpha angle of $\alpha=45^{\circ}$ the illuminated target acts like a dipole where either the $H H$ or $V V$ backscatter is zero. With a further increase of $\alpha$ the surface is characterized by an anisotropic dihedral scattering where the $H H \neq V V$ and the phase difference is $180^{\circ}$. At its maximum of $\alpha=90^{\circ}$, one can obtain an isotropic double bounce scattering mechanism (Cloude and Pottier, 1997). As a consequence, the polarimetric alpha angle, jointly used with the Entropy, gives a first impression of the dominant scattering mechanisms (Cloude and Pottier, 1997; Hellmann et al., 1999).

Cloude (1999), Cloude and Lewis (2000) as well as Hajnsek et al. (2003) first introduced the Anisotropy as a potential roughness estimator, which is only dependent from the geometrical properties of a given surface and independent from its dielectric properties as well as the local incidence angle. The Anisotropy $(A)$ is defined as:

$A=\frac{\lambda_{2}-\lambda_{3}}{\lambda_{2}+\lambda_{3}}$

It ranges from zero to one, where the eigenvalues of the coherency matrix $[\mathbf{T}]$ are $\lambda_{1} \geq \lambda_{2} \geq \lambda_{3} \geq 0$.

As obvious from (7), the Anisotropy defines the relation between the second and third eigenvalues and is therefore a measure of the secondary scattering mechanisms. As a consequence the Anisotropy is a very noisy parameter due to the measurement of the weak third eigenvalue $\lambda_{3}$ close to the system noise floor (Schuler et al., 2002; Hajnsek et al., 2003).

For low Anisotropy values, two equally strong scattering processes are present, while a high Anisotropy indicates the presence of only one strong secondary scattering process with a negligible third scattering mechanism (Cloude and Pottier, 1997).

However, the deployment of the Anisotropy comprises some constraints which are related to its physical meaning. Under the presence of vegetation, the Anisotropy decreases, due to an increase in importance of the third eigenvalue, and results therefore in an overestimation of roughness (Hajnsek et al., 2003). As a consequence the Anisotropy is only applicable for surface scatter regions, e.g. bare soil areas or areas with sparse vegetation with one strong scattering mechanism (Cloude and Pottier, 1997; Cloude, 1999; Hajnsek et al., 2003). Another limitation is given by an insensitiveness of $A$ for roughness values above $k s=1$ where A saturates and is therefore almost decorrelated (Hajnsek et al., 2003).

Dependent on the roughness conditions the Anisotropy A, can be inverted using two different linear approaches. For smooth areas Cloude and Lewis (2000) suggest:

$k s=1.25-2 A$

while for rougher surfaces Cloude (1999) recommends:

$k s=1-A$

As shown by Mattia et al. (1997), using PolSAR data over the Matera test site (Italy) and the Chickasha test site (USA), the magnitude of the complex circular coherence $\left(\left|\rho_{R R L L}\right|\right)$ is sensitive to roughness and insensitive to dielectric properties, respectively soil moisture of the illuminated target. The magnitude of the complex circular right-right left-left coherence is defined as (Mattia et al., 1997):

$$
\left|\rho_{R R L L}\right|=\frac{\left\langle\left|S_{R R} S_{L L}^{*}\right|\right\rangle}{\sqrt{\left\langle\left|S_{R R}\right|^{2}\right\rangle\left\langle\left|S_{L L}\right|^{2}\right\rangle}}
$$

with $\mathrm{S}_{R R}=$ right-right handedness, $\mathrm{S}_{L L}=$ left-left handedness of the rotation of the electric field vector about the line of sight. By definition $\left|\rho_{R R L L}\right|$ ranges similar as the Anisotropy from zero to one. In their investigations, Mattia et al. (1997) proved a nearly linear increase of $\left|\rho_{R R L L}\right|$ with a decrease in roughness. For rough fields, they measured values of $\left|\rho_{R R L L}\right|$ in a range of 0.2 to 0.05 while smooth fields showed values of $\left|\rho_{R R L L}\right|$ in a range of 0.6 to 0.5 .

In further investigations Schuler et al. (2002) approved this sensitivity of $\left|\rho_{R R L L}\right|$ but established a stronger relationship between the soil surface roughness and the real part of the circular coherence $\left(\operatorname{Re}_{[\rho R R L L]}\right)$ for a wide range of natural soil surfaces and different frequencies. The real part of the circular coherence is defined as (Schuler et al., 2002):

$\operatorname{Re}_{[\rho R R L L]}=\left[\frac{\left\langle\left|S_{H H}-S_{V V}\right|^{2}\right\rangle-4\left\langle\left|S_{H V}\right|^{2}\right\rangle}{\left\langle\left|S_{H H}-S_{V V}\right|^{2}\right\rangle+4\left\langle\left|S_{H V}\right|^{2}\right\rangle}\right]$ 
The advantage of using only the real part of the circular coherence as compared to the complex coherence is due to the fact that the imaginary part is very sensitive to unsymmetrical scattering contributions caused by vegetation (Schuler et al. 2002). Its insensitivity to the dielectric constant has further been proven in several investigations (Schuler et al. 2002, Thiel 2003). However for an azimuthal symmetric surface both estimators are the same, e.g. $\left|\rho_{R R L L}\right|$ is real and equals therefore $\operatorname{Re}_{[\rho R R L L]}$. Using $\operatorname{Re}_{[\rho R R L L]}$ rather than $\left|\rho_{R R L L}\right|$ has both advantages and disadvantages. When azimuth terrain slopes are present, the magnitude of $\operatorname{Re}_{[\rho R R L L]}$ is reduced and therefore $\operatorname{Re}_{[\rho R R L L]}$ is sensitive to large scale azimuthal slopes (Schuler et al., 2002). However these effects are correctable by using an external digital elevation model (DEM) (Lee et al., 2000). For this investigation an already terrain corrected SAR product (GTC) is utilized, therefore a further correction of large scale azimuth slopes is not required.

In their investigations Schuler et al. (2002) carried out an extensive comparison of $\left|\rho_{R R L L}\right|$ and $A$. They concluded that both soil surface roughness estimators are in general not the same, however in present of azimuth symmetric scatter the estimators lead to the same results. This condition of azimuthal symmetry is true for some natural scenes and can be illustrated as follows. For the special case of azimuth symmetric scatter the coherency matrix $[\mathbf{T}]$ is diagonal and the eigenvalues can be expressed as (Hajnsek 2001):

$$
\begin{aligned}
& \lambda_{1}=\left\langle\left|S_{H H}+S_{V V}\right|^{2}\right\rangle \\
& \lambda_{2}=\left\langle\left|S_{H H}-S_{V V}\right|^{2}\right\rangle \\
& \lambda_{3}=4\left\langle\left|S_{H V}\right|^{2}\right\rangle
\end{aligned}
$$

The fact that $A$ and $\left|\rho_{R R L L}\right|$ are the same for this case can be easily observed by incorporating (12) in (7) which is than equivalent to (11).

Indeed, for ks $<0.5, \operatorname{Re}_{[\rho R R L L]}$ is more sensitive to roughness than $A$ which is related to the noisy third eigenvalue, especially for those smooth areas with low backscatter close to the system noise floor (Schuler et al., 2002). As a consequence, for smooth areas and/or areas covered with vegetation, $\operatorname{Re}_{[\rho R R L L]}$ is the preferable roughness estimator.

For the spatial derivation of micro-scale soil surface roughness, the Anisotropy, $\left|\rho_{R R L L}\right|$ and $R e_{[\rho R R L L]}$ were calculated by applying a $5 \times 5$ boxcar filter on the despeckled L-band single look complex data.

\section{Results}

\subsection{In-field roughness measurements}

As described in Sect. 2.2.1, in-field micro-scale soil surface roughness was obtained from micro-DSMs, determined by photogrammetric image analysis. As can be seen from Fig. 5 it is possible to easily distinguish between different soil clods

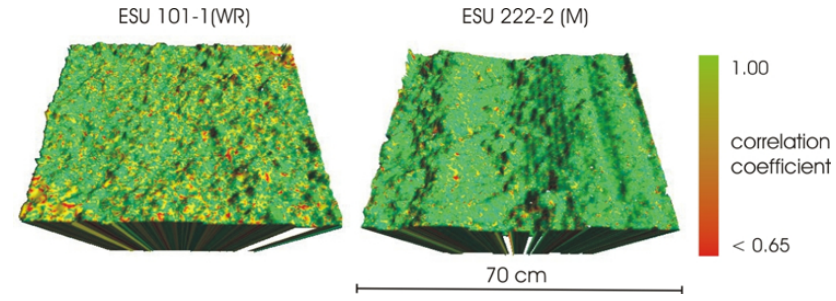

Fig. 5. Correlation coefficients of the matching process for two different sample points (101-1/222-2) and roughness states.

and even between small aggregates. The bundle block adjustment revealed a sub millimeter precision for the object coordinates. Triangulation resulted in a precision $z=0.8 \mathrm{~mm}$ in the vertical direction and $x y=0.37 \mathrm{~mm}$ in the horizontal direction related to the manually measured GCPs. The deployed matching strategies lead to a successful matching rate (pixels showing a correlation $>0.65$ ) of approximately $72 \%$ of all possible matches in all stereo pairs. Mismatches mostly appear in areas where three main factors occur: low image contrast, soil clod obstruction in both images and strong height difference between adjacent pixels. In regions where these factors are valid, the matching algorithm fails or leads to low correlation coefficients (see Fig. 5). However, the aim of the presented study was to develop an easy-to-apply standard procedure which allows for a rapid image acquisition near time the radar data recordings. Nevertheless, the derived DSMs showed good agreement with the highly accurate reference points with a mean absolute error of $1.2 \mathrm{~mm}$ and a RMSE of $1.6 \mathrm{~mm}$ in vertical direction. Compared to literature, these accuracies are sufficiently high (Rieke-Zapp and Nearing, 2005; Wegmann et al., 2001; Warner, 1995; Taconet and Ciarletti, 2007).

From the obtained micro-DSM, the RMS Heights are calculated for each sample point and date using Eqs. (1)-(3). Table 1 summarizes the main statistics of the calculated infield RMS Heights for each field separately, while Figs. 6-9 give an overview of the obtained roughness values for each field and campaign date separately. As can be seen from Fig. 6 and Table 1, the highest values for $s$ occur on the maize field 222, while the fields under winter resistant vegetation $(101,250$ and 440$)$ are much smoother with $s \approx 1 \mathrm{~cm}$. To assess the directionality of the in-field roughness, $\bar{s}_{x(y)} / \bar{s}_{y(x)}$ is calculated and the results are displayed in Fig. 9. As can be seen most sample points are dominated by an anisotropic roughness pattern with a direction perpendicular to the tillage pattern.

As roughness changes with its length/area over which it is estimated (see Sect. 2.2.1), we assessed its under- or overestimation by calculating for each DSM different sub-DSMs for both directions. Therefore we reduced subsequently each DSM by $0.2 \mathrm{~mm}$ in the $\mathrm{x}$ direction (respectively y direction) and calculated for each reduced DSM the RMS Heights parallel $\left(\bar{s}_{x(y)}\right)$ and perpendicular $\left(\bar{s}_{y(x)}\right)$ to the tillage direction. 
Table 1. Mean statistical characteristics of RMS Height measurements.

\begin{tabular}{lcccccc}
\hline & $101(\mathrm{WR})$ & $102(\mathrm{SB})$ & $222(\mathrm{M})$ & $250(\mathrm{WW})$ & $440(\mathrm{WB})$ & $460(\mathrm{SB})$ \\
\hline $\mathrm{s}$ & 0.84 & 1.07 & 1.74 & 0.9 & 0.9 & 1.29 \\
$\mathrm{~s}_{\mathrm{STD}}$ & 0.14 & 0.25 & 0.57 & 0.13 & 0.1 & 0.38 \\
$\mathrm{~s}_{x}$ & 0.61 & 0.56 & 0.77 & 0.52 & 0.53 & 0.65 \\
$\mathrm{~s}_{x}$ STD & 0.14 & 0.25 & 0.36 & 0.24 & 0.23 & 0.28 \\
$\mathrm{~s}_{y}$ & 0.72 & 0.81 & 1.45 & 0.72 & 0.71 & 1.04 \\
$\mathrm{~s}_{y}$ STD & 0.19 & 0.42 & 0.69 & 0.33 & 0.31 & 0.52 \\
\hline
\end{tabular}

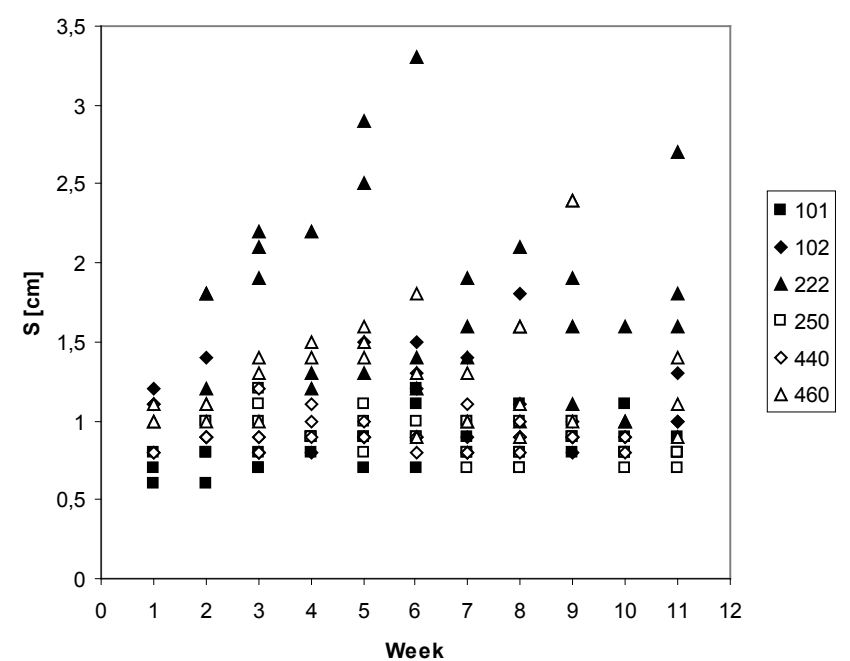

Fig. 6. RMS Height variability for each sample point and campaign date.

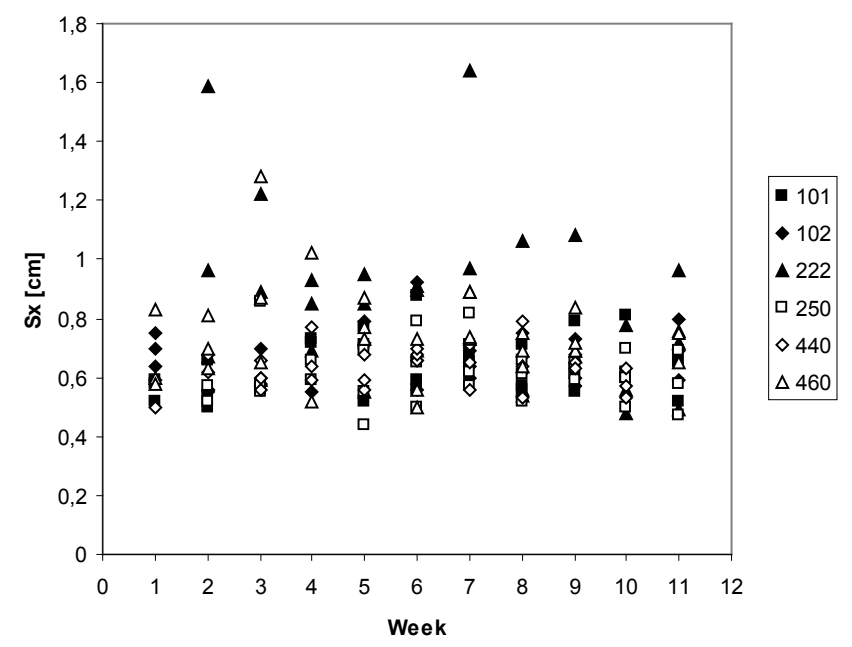

Fig. 7. RMS Height variability parallel to the tillage direction for each sample point and campaign date.

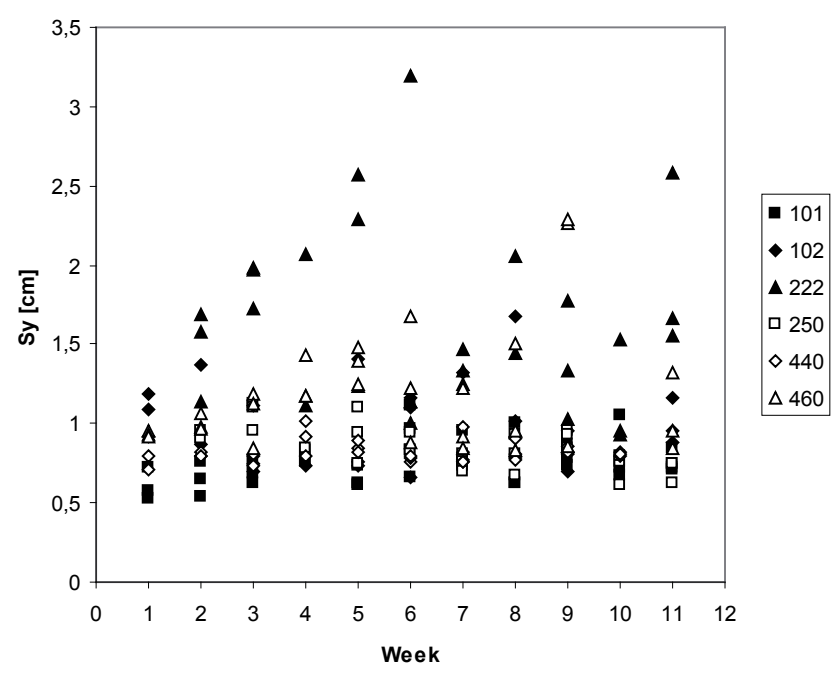

Fig. 8. RMS Height variability perpendicular to the tillage direction for each sample point and campaign date.

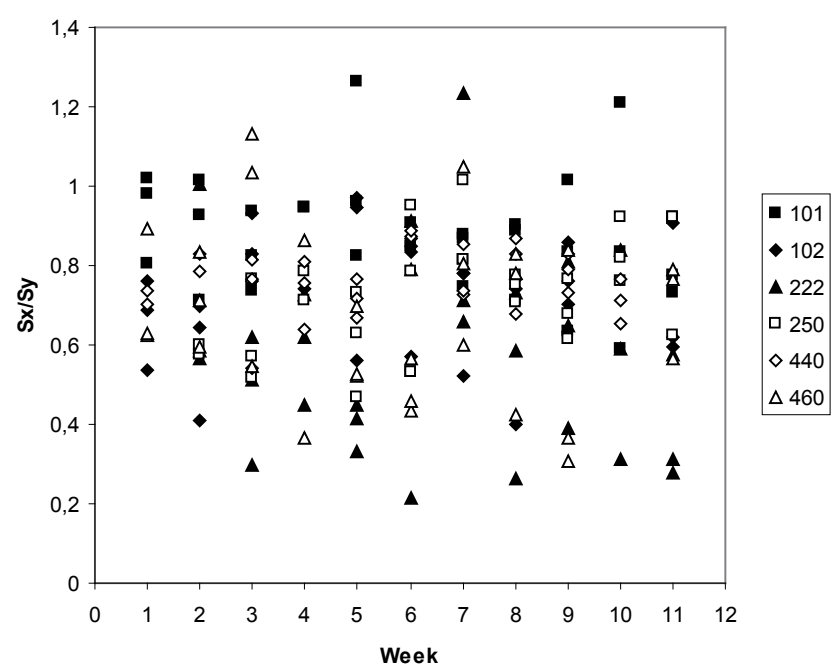

Fig. 9. Variability of the $\bar{s}_{x(y)} / \bar{s}_{y(x)}$ ratio showing directional effects in roughness for each sample point and campaign date. 
Results of three representative DSMs (smooth, medium and rough) are given in Fig. 10. It is obvious, that the size of the proper DSM is dependent from the direction of the tillage pattern. As the RMS Height perpendicular to the tillage direction saturates almost after $15-20 \mathrm{~cm}$, the RMS Height parallel to the tillage pattern shows no saturation effects and is nearly random over the acquired area, meaning that the chosen sampling area is to small to represent the roughness in parallel to the tillage direction. However, this needs to be further investigated in future.

\subsection{Derivation of soil surface roughness on the field scale}

Figure 11 shows the comparison of the calculated potential roughness estimators, based on Eqs. (7), (10) and (11), for 19 April 2006. As theory predicts, the Anisotropy $A$ appears much noisier than $\left|\rho_{R R L L}\right|$ and $\operatorname{Re}_{[\rho R R L L]}$, due to its calculation from the second and third eigenvalues (see Eq. 7) (Cloude, 1999; Hajnsek, 2001; Schuler et al., 2002). The $R e_{[\rho R R L L]}$ reveals the highest level of detail and does not appear as noisy as the others.

Schuler et al. (2002) and Mattia et al. (1997) showed in their investigations that the polarimetric coherence decreases with an increase in surface roughness. Thus, smooth areas with large enough backscatter intensities appear in bright colours in $\left|\rho_{R R L L}\right|$ images (see Fig. 11, middle). Contrary to $\left|\rho_{R R L L}\right|$, the images of $\operatorname{Re}_{[\rho R R L L]}$ appear different: the values for $R e_{[\rho R R L L]}$ increases with an increase of surface roughness (Thiel, 2003). Note that in contrast to $A$ and $\left|\rho_{R R L L}\right|$ values of $\operatorname{Re}_{[\rho R R L L]}$ are in the range of -1 to +1 . Following the approches of Cloude (1999) as well as Cloude and Lewis (2000), high values for the Anisotropy Aindicate smooth areas while lower Anisotropy regions show rougher areas. As taken from Fig. 11 all three estimators allow to distinguish between different roughness states within and between several fields.

For the derivation of soil surface roughness on field scale, correlation coefficients have been calculated for each field and each campaign date between the RMS Heights and the calculated radar parameters (Figs. 12-13). As can be seen from Fig. 12, the correlation coefficients for all fields over the whole campaign are quit low with a maximum for the Anisotropy on field 102 with $r=0.44$. Note the positive sign of the correlation for the whole fields (except field 250) and $A$, which indicates a proportional relationship and is contrary to the proposed inversion schemes by Cloude (1999) as well as Cloude and Lewis (2000). For $\left|\rho_{R R L L}\right|$ the mean correlation coefficient is $r=0,2$ which indicates a weak positive relationship, which is similar to $A$. Indeed, the theoretical description by Mattia et al. (1997) as well as the investigation of Schuler et al. (2002) showed a negative relationship, meaning that high coherence values indicate a smooth surface. For the real part of the complex circular coherence $R e_{[\rho R R L L]}$ no consistent correlation for the different fields can be observed. Even for the two sugar beet fields (102 and 460) opposite
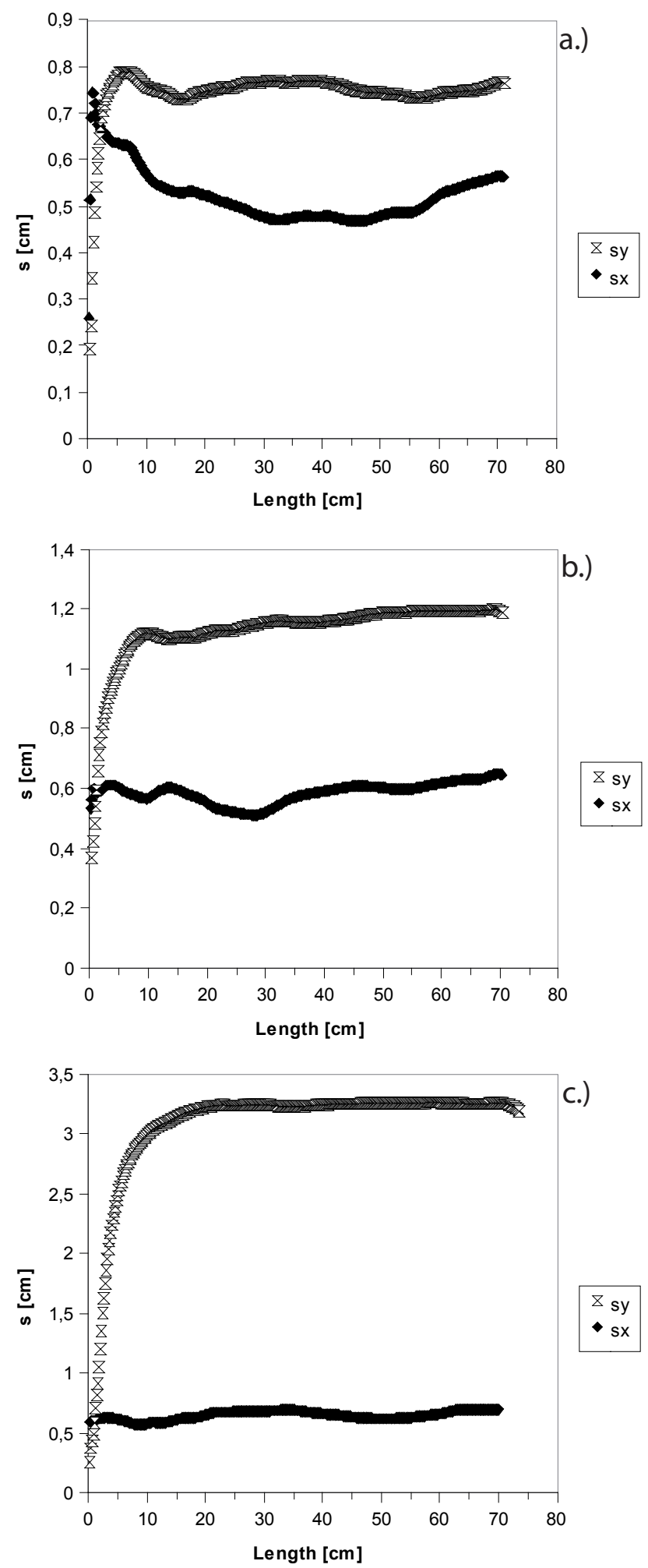

Fig. 10. Variation of RMS Heights in dependency from the size of the sampling area. (a) smooth DSM with $s=0.6 \mathrm{~cm}$, (b) medium DSM with $s=1.3 \mathrm{~cm}$ and (c) rough DSM with $s=3.3 \mathrm{~cm}$. 

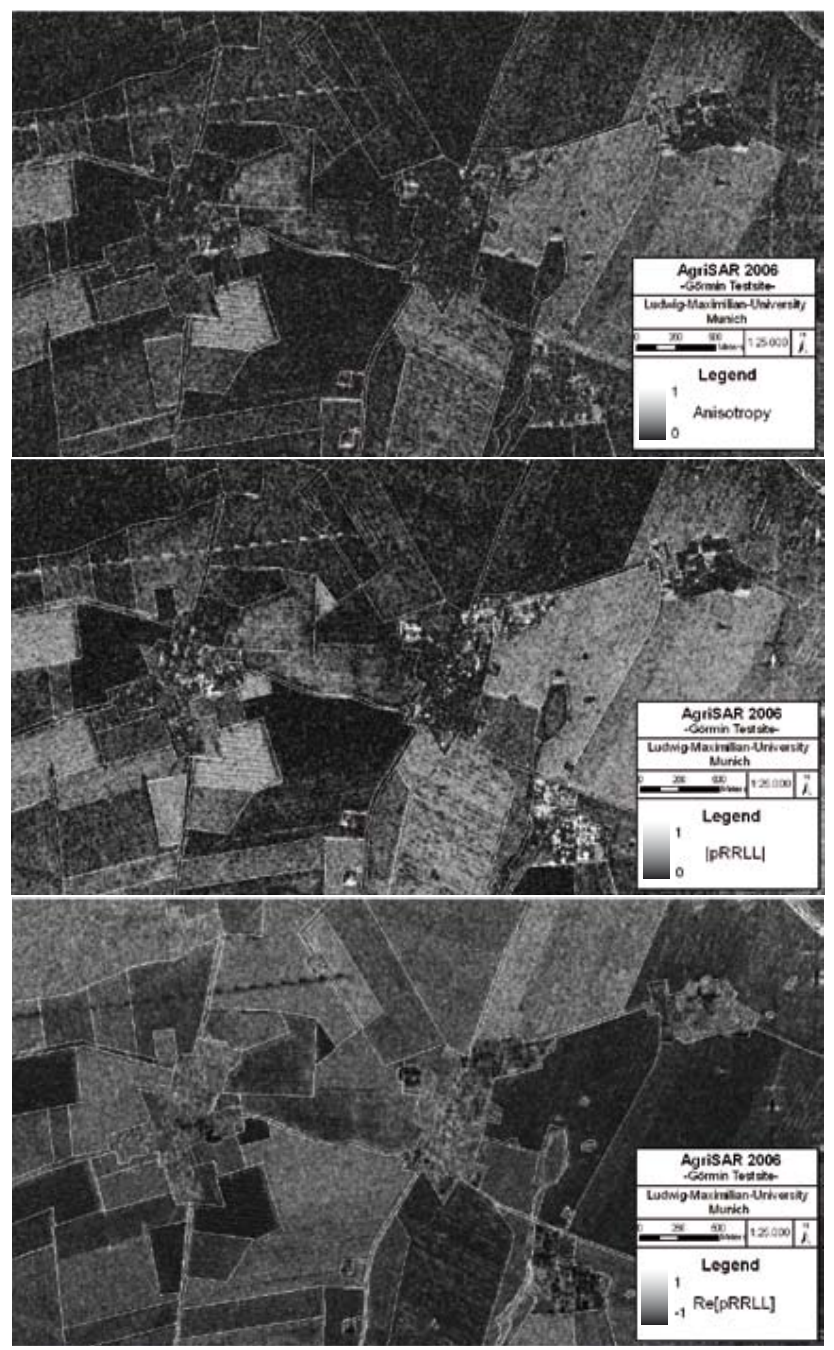

Fig. 11. Calculated roughness estimators (Anisotropy, Circular Coherence and Real Part of the Circular Coherence) for 19 April 2006.

signs are given for the correlation coefficients. This could be related to the presence of vegetation which cause an overestimation of $k s$ and superimposes therefore the good correlation coefficients between $k s$ and the radar parameters on bare soil fields (see Fig. 15). As investigations of Thiel (2003) have shown, there is in general a positive proportional relationship between $k s$ and $R e_{[\rho R R L L]}$ which is also observable within Fig. 10.

To study the effect of vegetation on the roughness retrieval we calculated for the bare soil fields (102, 222 and 460) for each campaign date the mean correlation coefficient which are shown in Fig. 13. While $R e_{[\rho R R L L]}$ and $\left|\rho_{R R L L}\right|$ show a very similar trend over the whole campaign, the Anisotropy $A$ changes its sign nearly random, which led us to conclude that it is not suitable for roughness retrieval. Indeed, especially for the first three campaign dates, a strong correlation between $R e_{[\rho R R L L]},\left|\rho_{R R L L}\right|$ and $k s$ in range of $r=0.65$ to $r=0.97$ can be observed. As theory reveals, for

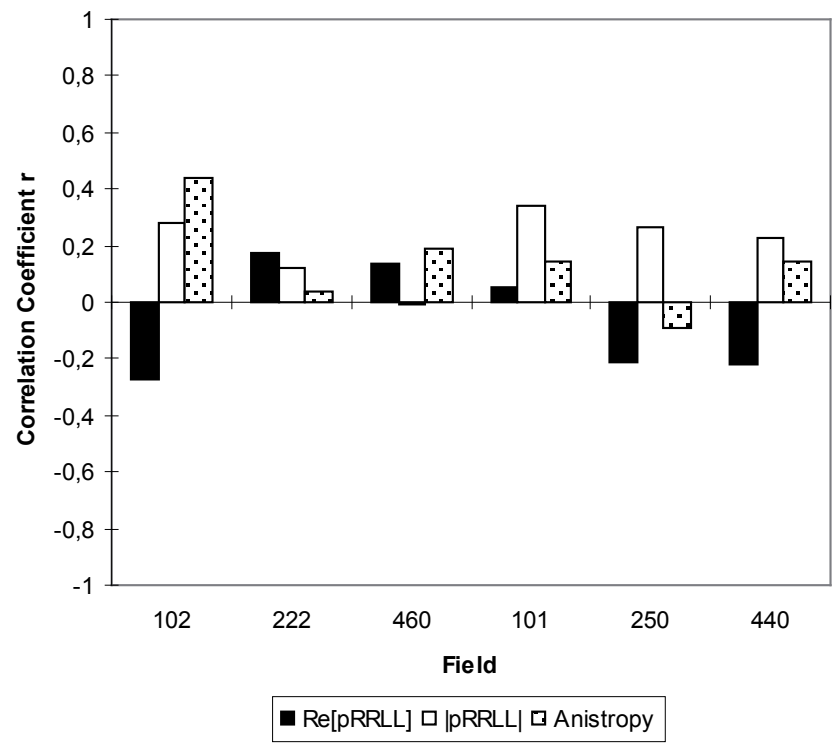

Fig. 12. Correlation coefficients $r$ between $k s$ and polarimetric roughness estimators for each field and whole campaign.

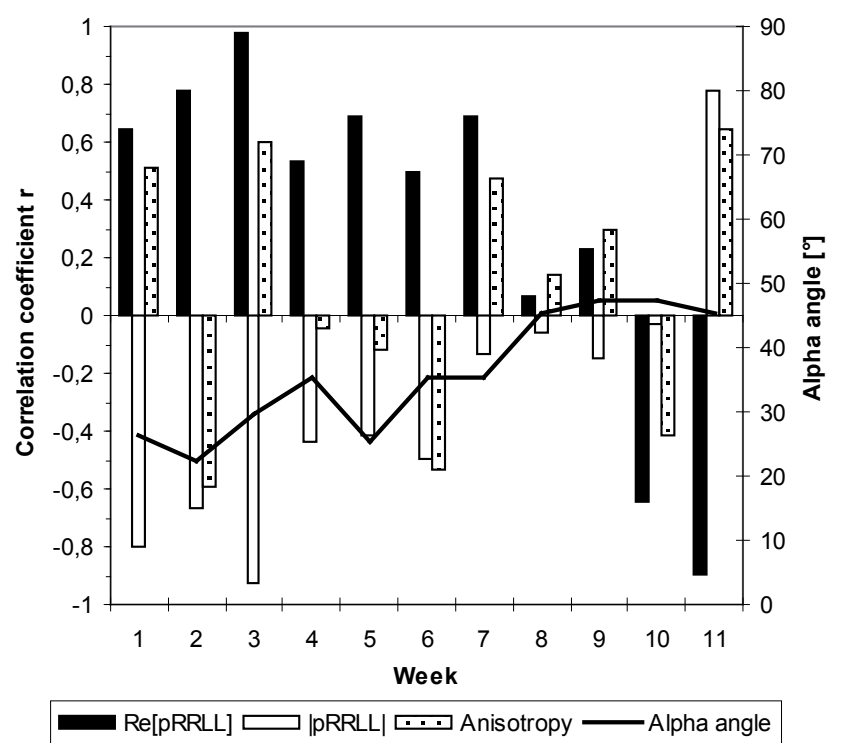

Fig. 13. Correlation coefficients $r$ between $k s$ and polarimetric roughness estimators and mean polarimetric alpha angle for the summer vegetation field at each campaign.

an azimuthal symmetric surface both estimators are the same and yield in the same values for $r$. The small discrepancies can be explained due to the non isotropic behaviour of the fields (Fig. 9) which reduces the similarity of both estimators (Schuler et al., 2002). However, with development of vegetation the correlation between both estimators and $k s$ is reduced showing its minimum at the eighth campaign date and then increases with an opposite sign for both estimators revealing the effect of vegetation on the derivation. 


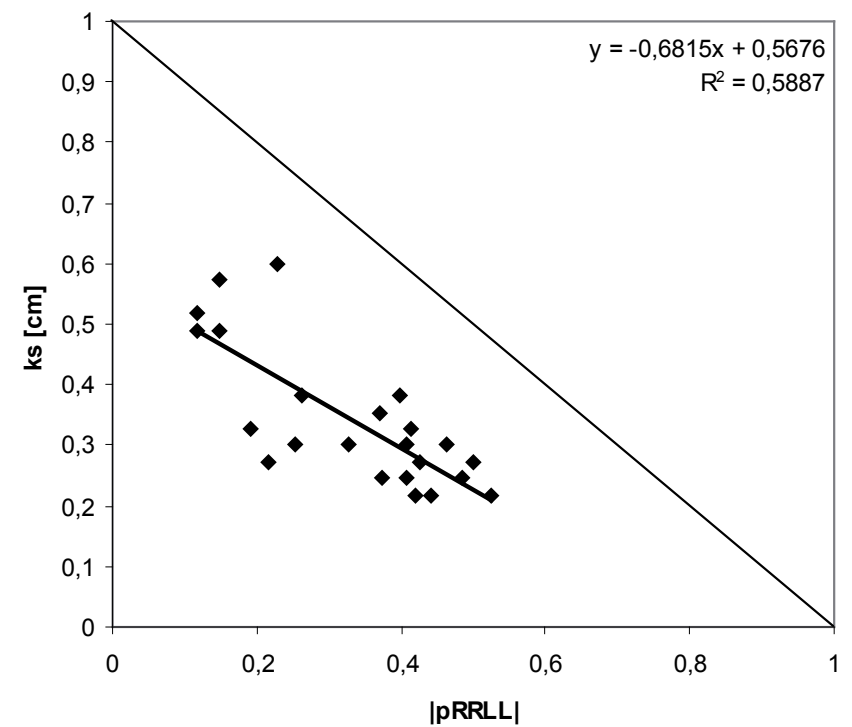

Fig. 14. Scatterplot for $k s$ and $\left|\rho_{R R L L}\right|$ for areas $\alpha<40^{\circ}$ at the first three campaign dates.

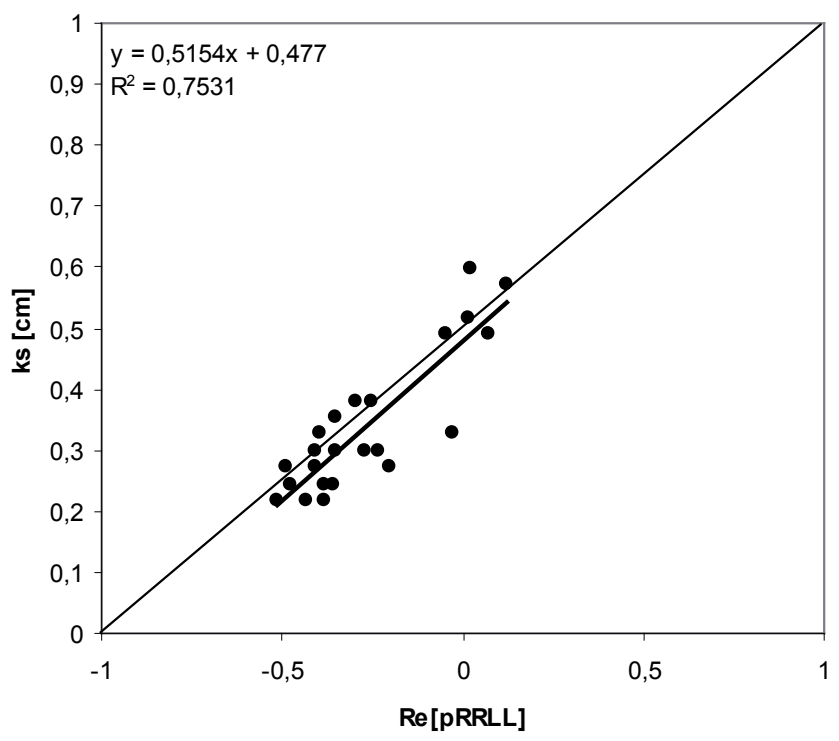

Fig. 15. Scatterplot for $k s$ and $R e_{\left[\rho_{R R L L}\right]}$ for areas $\alpha<40^{\circ}$ at the first three campaign dates.

To define a threshold to which a derivation is suitable, we tested several vegetation dependent indices. As argued by Hajnsek (2001) the $H V / V V$-ratio $<0.07(-11 \mathrm{~dB})$ is a good measure for the separation of vegetated and bare soil surfaces. However, we could not confirm this threshold (data not shown). As a measure of the different scattering mechanisms, the polarimetric alpha angle is a good indicator of the different phenological stages. Therefore we plotted the $\alpha$ angle against the correlation coefficients as displayed in Fig. 13. As can be seen with an increase in $\alpha$, a decrease of $r$ for $\operatorname{Re}_{[\rho R R L L]},\left|\rho_{R R L L}\right|$ and $k s$ can be observed until

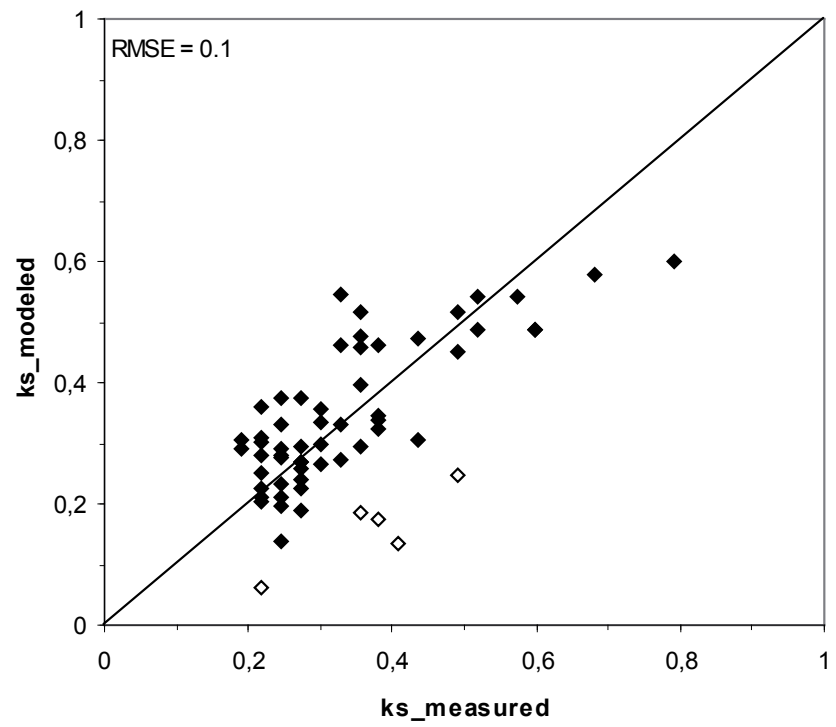

Fig. 16. Modeled versus measured $k s$ values for all sample plots with $\alpha<40^{\circ}$. Hollow rhombuses indicate sample points with strong directional effects.

its sign changes. An appropriate threshold seems to be an $\alpha$ angle $<40^{\circ}$, which is related to the surface scatter criterion proposed by Cloude and Pottier (1997), however it is not that strict and even allows high roughness values with an high Entropy to be included in the derivation.

\subsection{Multi temporal roughness derivation}

To develop an inversion scheme, we defined for the first three campaign dates an empirical relationship masking out all the values with $\alpha>40^{\circ}$, which allows us to calculate a regression based on bare soil conditions under a wide variety of roughness values. Scatterplots for both, the $\operatorname{Re}_{[\rho R R L L]}$ and $\left|\rho_{R R L L}\right|$ show a strong correlation to ks and are displayed in Figs. 14 and 15. However the correlation coefficient between $k s$ and $\operatorname{Re}_{[\rho R R L L]}$ is quite high and outperforms $\left|\rho_{R R L L}\right|$. Based on this correlation, we defined a linear inversion scheme which allows us to invert $k s$ from $\operatorname{Re}_{[\rho R R L L]}$ :

$k s=0.5154 \times \operatorname{Re}_{[\rho R R L L]}+0.477$

Using this relationship, we derived $k s$ from $R e_{[\rho R R L L]}$ for each campaign date on the remaining valid areas. A RMSE of 0.1 indicates a very accurate inversion model. Figure 16 shows a scatterplot for the modeled and measured $k s$ values. High $k s$ values are slightly underestimated while several other roughness values (in Fig. 16 indicated by hollow rhombuses) are also underestimated. However, these measured $k s$ values show a significant directional behavior leading to an overestimation of the in-field $k s$ values, as can be obtained from Fig. 9. 


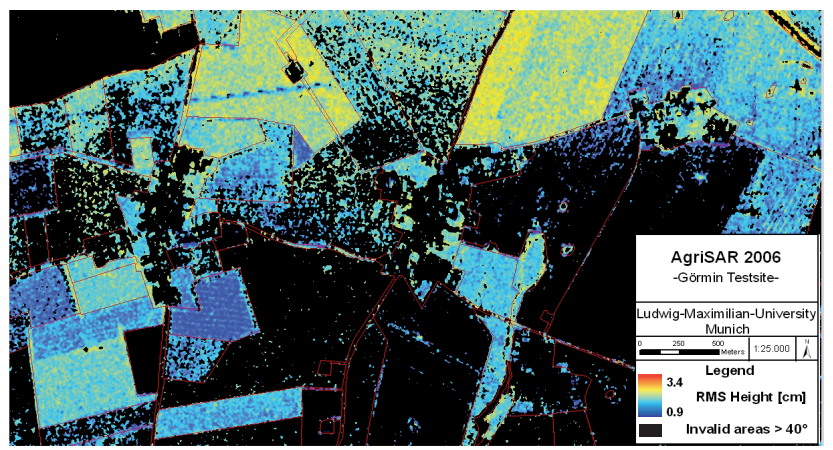

Fig. 17. Spatial distribution of $s$. Invalid areas with $\alpha>40^{\circ}$ are masked out black.

Finally, Fig. 17 shows the spatially derived values for $s$, were invalid areas with $\alpha>40^{\circ}$ (settlements, forests, vital vegetated areas) are masked out for April 19, 2006. As can be seen, the southern part of field 460 (sugar beet) appears much rougher as the northern part, which is due to ongoing agricultural practice during the first campaign date. While in the southern part the seed bed was already prepared, the northern part is still showing a crusted surface from the bare winter period.

\section{Potentials for hydrological model application - re- trieval of soil bulk density parameters}

This section discusses the potentials and limitations of the proposed roughness retrieval for direct use in hydrological models. As soil surface roughness play a crucial role in physically based soil erosion models, the assimilation of the derived roughness values into such models is considered beneficial to better describe the processes involved. However due to the lack of precipitation a soil erosion assessment is not reasonable. Results of a feasibility study on the use of roughness information in physically based hydro-ecological modeling will be presented.

In addition to soil texture (grain size), bulk density and derived variables such as porosity and void ratio are key parameters in hydrological modeling. Most widely used pedo-transfer-functions (PTF) for the calculation of hydroecological properties such as (un-)saturated conductivity are based on these parameters (Cosby et al., 1984; Rawls and Brakensiek, 1985; Woesten et al., 1999; Sobieraj et al., 2001). Further, porosity as well as void ratio are important indicators for the detection of mechanically compacted soils in agricultural environments. Typically, bulk density can be determined using Kopecky rings with known volume, while soil porosity is mostly measured using an air pycnometer (Schlichting et al., 1998; Sun et al., 2006). Alternatively, soil porosity $(n)$ as well as void ratio $(\varepsilon)$ can be calculated

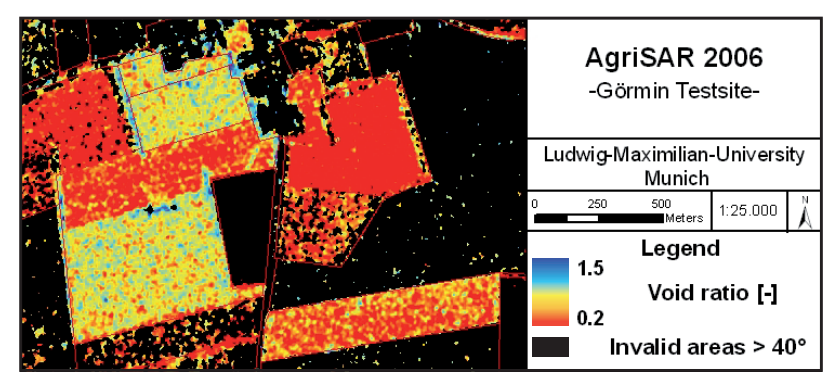

Fig. 18. Spatial derived void ratio for 19 April on both sugar beet fields(102+460). Invalid areas with an alpha angle $\alpha>40^{\circ}$ are masked out black.

Table 2. Statistical characteristics for bulk density parameters.

\begin{tabular}{lccc}
\hline & $\rho_{s}$ & $n[\%]$ & $\varepsilon[-]$ \\
\hline Mean & 1.43 & 45 & 0.89 \\
Min & 1.01 & 36 & 0.56 \\
Max & 1.69 & 62 & 1.6 \\
STD & 0.11 & 4.2 & 0.15 \\
\hline
\end{tabular}

from bulk density measurements using the following equations (Hartge and Horn, 1999):

$n=1-\frac{\rho_{s}}{\rho_{F}}$

$\varepsilon=\frac{n}{1-n}$

Where $n$ denotes soil porosity in $(\%) ; \rho_{s}$ is the bulk density of the given soil $\left(\mathrm{g} / \mathrm{cm}^{3}\right)$ and $\rho_{F}$ is the bulk density of the solid particles, where for quartzous soils $\rho_{F} \approx 2.65 \mathrm{~g} / \mathrm{cm}^{3}$.

However, there are some drawbacks in using these classical methods. First, destructive measurements using Kopecky rings or the air pycnometer do not allow for a multi temporal analysis. Secondly, they are limited to a small area (plot scale) and therefore time-, labor- and cost-consuming for field scale assessments.

Sun et al. (2006) introduced the potential of using roughness information, derived from a $3 \mathrm{~d}$ laser device, to obtain soil porosity. Using a linear fit, they predicted porosity from RMS Heights for different roughness conditions of a silty loam soil. The hypothesis is based on the assumption that changing roughness due to tillage practice or precipitation alters only volume but not mass of the soil column (Hartge and Horn 1999) and thus introduces a change in soil porosity.

To verify the approach suggested by Sun et al. (2006), correlation coefficients between the in-field roughness measurements and the bulk parameters calculated from Eqs. (14) and (15) are determined. To avoid any influence from vegetation, only bare fields were considered. Table 2 summarizes 
Table 3. Correlation between $\mathrm{s}$ and soil bulk density parameters $\left(R^{2}=\right.$ coefficient of determination, $r=$ correlation coefficient, $m=$ slope, $b=$ axis intercept).

\begin{tabular}{lcrrr}
\hline Parameter & $R^{2}$ & $r$ & $m$ & $b$ \\
\hline$\rho_{s}$ & 0.55 & -0.74 & -0.32 & 1.90 \\
$n$ & 0.55 & 0.74 & 12.14 & 28.28 \\
$\varepsilon$ & 0.60 & 0.78 & 0.49 & 0.16 \\
\hline
\end{tabular}

the statistics of measured bulk density values while Table 3 summarizes the results from this analysis.

A good relationship between the indicated parameters can be noted, while the void ratio in the uppermost layer is correlated stronger to $s$ than the bulk density and porosity (see Table 3). This is in good agreement with the results of Sun et al. (2006).

Applying a linear fit, we derived the spatial void ration for 19 April, for the bare soil field 102 and 460, as shown in Fig. 18. A first visual qualitative interpretation of the results indicates a well working algorithm. The still crusted surface on field 102 as well as the crusted northern part of field 460 show a very low void ratio while the already seed bed prepared southern part of field 460 shows significantly higher values. Result in form of an RMSE $=0.17 \mathrm{~g} / \mathrm{cm}^{3}$ indicate promising results, however there is still some potential for an enhanced bulk density parameter retrieval that has to be investigated with a larger amount of data in future studies.

\section{Summary and conclusions}

This study presents an approach for the spatial derivation of soil surface roughness using photogrammetry and radar remote sensing. Therefore several polarimetric roughness estimators have been correlated to a wide range of $k s$ values, showing that the real part of the complex circular coherence is outperforming all the other estimators. However, as theory reveals, for azimuth symmetric bare soil surfaces $\operatorname{Re}_{[\rho R R L L]}$ and $\left|\rho_{R R L L}\right|$ are the same, while for asymmetric surfaces, due to a directional behaviour of the surface, differences in both occur. In presence of vegetation, the retrieval algorithm leads to an overestimation of roughness and is therefore not suitable for an operational use. However, using the polarimetric alpha angle (Cloude and Pottier, 1996) for masking out areas with $\alpha>40^{\circ}$ seems to be a suitable threshold for a robust roughness retrieval of various roughness conditions even under (short or dry/ripe) vegetation leading to a RMSE $=0.1$. However for high $k s$ values $(k s \geq 0.8)$ an underestimation using the developed inversion scheme could be ascertained. In investigations of Hajnsek (2001) and Schuler et al. (2002), a random distribution of $\operatorname{Re}_{[\rho R R L L]}$ and $\left|\rho_{R R L L}\right|$ for $k s>1$ is reported, which is in good accordance with our results.
It is shown that the deployed photogrammetric method allows a fast and adequate retrieval of roughness information. However, the role of the scale dependent calculations of $\mathrm{s}$ needs to be further investigated in future studies. Even if earlier papers from Taconet and Ciarletti (2007) proved a good representation of the roughness determination for the deployed horizontal coverage $\left(0.5 \mathrm{~m}^{2}\right)$, uncertainties remain, which are especially given in parallel to the tillage direction were a larger sampling area is necessary. Future investigations, to assess this effect on roughness retrieval from SAR data, are mandatory.

However, our results indicate that spatially determined soil surface roughness from remote sensing can support the parameterization of spatially explicit hydrological models, in this case by providing distributed values of driving variables. It is shown in a first assessment that soil bulk parameters of the upper few centimetres of the soil column, such as bulk density, porosity and void ratio, can be discriminated from surface roughness. However, even though a dependency of these bulk parameters from roughness can be noted, the approach needs further research with regard to different uncertainties:

- The correlation between roughness parameters and bulk parameters is only strong for fresh harrowed fields. For small values of $\mathrm{s} \leq 1 \mathrm{~cm}$ the bulk parameters are randomly distributed.

- Using the regionalization approach suggested in this study, error propagation will lead to large RMSE values. Therefore, a better roughness retrieval needs to be achieved.

Besides those constraints, the approach is very promising. For future investigations, an enhanced roughness retrieval has to comprise four major improvements:

- To enhance the in-field roughness retrieval, the image acquisition set up has to be improved by better illumination and to solve the appearance of obstructed areas more than two image pairs could remediate (Luhmann, 2003; Wiggenhagen and Raguse, 2003). To solve the problem of mismatches between adjacent pixels with strong height differences, a broad variety of appropriate matching strategies have to be developed to enhance the matching process.

- The effect of directionality on roughness retrieval needs to be investigated in more depth by comprising a larger amount of roughness in-situ measurements to achieve a better understanding of those effects.

- To reduce uncertainties in roughness measurements, due to too small sampling areas the horizontal coverage of future measurement systems has to be increased especially in the direction parallel to the tillage pattern. 
- For a better separation of vegetation effects different decomposition theorems as well as the deployment of PolInSAR techniques will be necessary.

Acknowledgements. The authors would like to thank ESA for funding the AgriSAR 2006 campaign. Rieke-Zapp (University of Bern) is gratefully acknowledged for providing the Rollei $\mathrm{d} 7$ metric camera and for assistance and support during the photogrammetric processing.

Edited by: W. Wagner

\section{References}

Allmaras, R. R., Burwell, R. E., Larson, W. E., and Holt, R. F.: Total porosity and random roughness of the interrow zone as influenced by tillage, USDA Conservation Research Report, 7, 1966.

Bertuzzi, P., Rauws, G., and Courault, D.: Testing roughness indices to estimate soil surface roughness changes due to simulated rainfall, Soil Till. Res., 17, 87-99, 1990.

Cerdan, O., Souchère, V. Lecomtze, V. Couturier, A., and Le Bissonnais, Y.: Incorporating soil surface crusting processes in an expert-based runoff model: Sealing and Transfer by Runoff and Erosion related to Agricultural Management - STREAM. Catena Vol., 189-205, 2001.

Cloude, S. R.: Eigenvalue parameters for surface roughness studies. Proceedings of SPIE Conference on Polarization: Measurement, analysis and remote Sensing II, Denver, Colorado, USA, 1999.

Cloude, S. R. and Lewis, G. D.: Eigenvalue Analysis of Mueller Matrix for Bead Basted Aluminium Surfaces, SPIE Polarisation Analysis and Measurement III, Proc. SPIE, AM107, JulyAugust 2000, 2000.

Cloude, S. R. and E. Pottier: A review of target decomposition theorems in radar polarimetry. IEEE T. Geosci. Remote Sens., 34, 498-518, 1996.

Cloude, S. R. and Pottier, E.: An entropy based classification scheme for land applications of polarimetric SAR. IEEE T. Geosci. Remote Sens. 35(1), 68-78, 1997.

Cosby, B. J., Hornberger, G. M., Clapp, R. B., and Ginn, T. R.: A statistical exploration of the relationships of soil moisture characteristics to the physical properties of soils, Water Resour. Res., 20, 682-690, 1984.

Currence, H. D. and Lovely, W. G.: The analysis of soil surface roughness, Trans. ASAE, 13, 710-714, 1970.

Darboux, F., Gascuel-Odoux, C. and Davy, P.: Effects of surface water storage by soil roughness on overland-flow generation, Earth Surf. Proc. Landforms, 27, 223-233, 2002.

Davidson, M. W. J., Le Toan, T., Mattia, F., Satalino, C., Manninen, T., and Borgeaud, M.: On the characterization of agricultural soil roughness for radar remote sensing studies, IEEE T. Geosci. Remote Sens., 38, 630-640, 2000.

Ebner, H.: Self calibrating block adjustment. Proceedings XIII Congress of the International Society of Photogrammetry, Helsinki, 1976.

Farres, P. J.: Some observations on the stability of soil aggregates to raindrop impact, Catena, 7, 223-231, 1980.

Fohrer, N., Berkenhagen, J., Hecker, J.-M., and Rudolph, A.: Changing soil and surface conditions during rainfall single rainstorms/ subsequent rainstorms, Catena, 37, 355-375, 1999.
Hajnsek, I.: Inversion of surface parameters from polarimetric SAR. PhD-Thesis Friedrich-Schiller-University Jena, Germany, 238 pp., 2001.

Hajnsek, I., Bianchi, R., Davidson, M., D‘Urso, G., GomezSanchez, J., Hausold, A., Horn, R., Howse, J., Loew, A., LopezSanchez, J., Ludwig, R., Martinez-Lozano, J., Mattia, F., Miguel, E., Moreno, J., Pauwels, V., Ruhtz, T., Schmullius, C., Skriver, H., Sobrino, J., Timmermans, W., Wloczyk, C., and Wooding, M.: AgriSAR 2006 Airborne SAR and Optics Campaigns for an improved monitoring of agricultural processes and practices, European Geoscience Union (EGU), General Assembly, 15-20 April 2007, Vienna, Austria, 2007.

Hajnsek, I., Pottier, E., and Cloude, S. R.: Inversion of surface parameters from polarimetric SAR, IEEE T. Geosci. Remote Sens., 41, 727-744, 2003.

Hartge, K. H., and Horn, R.: Einführung in die Bodenphysik, 3. Aufl. Ferdinand Enke, Stuttgart, 304 pp., 1999.

Hellmann, M., Jager, G., Kratzschmar, E., and Habermeyer, M.: Classification of full polarimetric SAR-data using artificial neural networks and fuzzy algorithms, IEEE Proceedings IGARSS'99, Hamburg, 1995-1997, 1999.

Helming, K.: Die Bedeutung des Mikroreliefs für die Regentropfenerosion. Bodenökologie und Bodengenese Nr. 7, Berlin, Germany, 1992.

Lascelles, B., Favis-Mortlock, D., Parsons, T., and Boardman, J.: Automated digital photogrammetry: a valuable tool for smallscale geomorphological research for the non-photogrammetrist?, Trans. GIS, 6, 5-15, 2002.

Le Bissonnais, Y., Benkhada, Chaplot, V., Fox, D., King, D., and Daroussin, J.: Crusting, runoff and sheet erosion on silty loamy soils at various scales and upscaling from $\mathrm{m}^{2}$ to small catchments, Soil Till. Res., 46, 69-80, 1998.

Lee, J. S., Grunes, M. R., and De Grandi, G.: Polaimetric SAR speckle filtering and its impact on classification, IEEE T. Geosci. Remote Sens., 37, 2363-2373, 1997.

Lee, J. S., Schuler, D. L., and Ainsworth, T. L.: Polarimetric SAR data compensation for terrain azimuth slope variation, IEEE T. Geosci. Remote Sens., 38, 2153-2163, 2000.

Linden, D. R. and Van Doeren, D. M.: Parameters for characterizing tillage induced soil surface roughness, Soil Sci. Soc. Am. J., 50, 1560-1565, 1986.

Linder, W.: Digital Photogrammetry, A Practical Course. Springer Berlin, Heidelberg, New York, USA, 214 pp., 2006.

Loew, A., Ludwig, R., and Mauser, W.: Derivation of surface soil moisture from ENVISAT ASAR WideSwath and Image mode data in agricultural areas, IEEE T. Geosci. Remote Sens., 44, 889-899, 2006.

Loew, A. and Mauser, W.: Inverse modeling of soil characteristics from surface soil moisture observations: potential and limitations, Hydrol. Earth Sys. Sci., 5, 95-145, 2008.

LPS: Leica Photogrammetry Suite User Manual V 9.0, 2006.

Luhmann, T.: Nahbereichsphotogrammetrie - Grundlagen, Methoden und Anwendungen. Heidelberg, Germany, 586 pp., 2003.

Mattia, F., Le Toan, T., Souyris, J. C., De Carolis, G., Floury, N., Posa, F., and Pasquariello, G.: The effect of surface roughness on multi frequency polarimetric SAR data, IEEE T. Geosci. Remote Sens., 35, 954-966, 1997.

Oh, Y., Sarabandi, K., and Ulaby, F. T.: An empirical model and an inversion technique for rader scattering from bare soil surfaces, 
IEEE T. Geosci. Remote Sens., 30, 370-381, 1992.

Rawls, W. and Brakensiek, D.: Prediction of soil water retention properties for hydrologic modeling, Watershed Management in the Eighties, Proc. Symposium of Irrig. Drainage Div. ASCE, Denver, CO, USA, 30 April-1 May 1985, 293-299, 1985.

Rieke-Zapp, D. and Nearing, M. A.: Digital close range photogrammetry for measurement of soil erosion, The Photogrammetric Record, 20, 69-87, 2005.

Römkens, M. J. and Wang, J. Y.: Effect of tillage on surface roughness, Trans. ASAE 29, 429-433, 1986.

Santanello, J. A., Peters-Lidard, C. D., Garcia, M. E., Mocko, D. M., Tischler, M. A., Moran, S., and Thoma, D.: Using remotelysensed estimates of soil moisture to infer soil texture and hydraulic properties across a semi-arid watershed, Remote Sens. Environ., 110, 79-97, 2007.

Scheiber, R., Keller, M., Fischer, J., Horn, R., and Hajnsek, I.: Radar Data Processing, Quality Analysis and Level-1b Product Generation for AGRISAR and EAGLE campaigns. Proceedings AGRISAR and EAGLE Campaigns Final Workshop, 15-16 October 2007 ESA/ESTEC, Noordwijk, The Netherlands, available on CD, 2007.

Schlichting, E., Blume, H. P., and Stahr, K.: Bodenkundliches Praktikum. Blackwell, Berlin, Germany, 295 pp., 1995.

Schuler, D. L., Lee, J. S., and Kasilingam, D.: Surface roughness and slope measurements using polarimetric SAR data, IEEE T. Geosci. Remote Sens., 40, 687-698, 2002.

Sobieraj, J. A., Elsenbeer, H., and Vertessy, R. A.: Pedotransfer functions for estimating saturated hydraulic conductivity: implications for modeling storm flow generation, J. Hydrol., 251, 202-220, 2001.

Sommer, H.: Quantifizierung der Rauigkeit von Bodenoberflächen und Simulation hydromechanischer Prozesse anhand von Oberflächenmodelen. Aachen, Germany, 1997.

Sun, Y., Lin, J., Schulze Lammers, P., and Damerow, L.: Short communication. Estimating surface porosity by roughness measurement in a silt - loam field. J. Plant Nutr. Soil Sci., 169, 630-632, 2006.
Taconet, O. and Ciarletti, V.: Estimating soil roughness indices on a ridge-and-furrow surface using stereo photogrammetry, Soil Till. Res., 93, 64-76, 2007.

Thiel, C.: Measuring surface roughness on base of the circular polarization coherence as an input for simple inversion of the IEM model, Proceedings of PolInSAR Workshop, 14-16 January 2003, Frascati, Italy, 2003.

Thiel, Ch., Gruenler, S., Herold, M., Hochschild, V., Jaeger, G. and Hellmann, M.: Interpretation and Analysis of Polarimetric L-Band E-SAR-Data for the Derivation of Hydrologic Land Surface Parameters, IEEE Proceedings IGARSS'01, Sydney, available on CD, 2001.

Verhoest, N. E. C., De Baets, B., and Vernieuwe, H.: A TakagiSugeno fuzzy rule-based model for soil moisture retrieval from SAR under soil roughness uncertainty, IEEE T. Geosci. Remote Sens., 45, 1351-1360, 2007.

Verhoest, N. E. C., Lievens, H. Wagner, W. Álvarez-Mozos, J., Moran, S., and Mattia, F.: On the soil roughness parameterization problem in soil moisture retrieval of bare surfaces from synthetic aperture radar, Sensors, 8, 4213-4248, 2008.

Warner, W. S.: Mapping a three-dimensional soil surface with handheld 35 mm photography, Soil Till. Res. 34, 187-197, 1995.

Wegmann, H., Rieke-Zapp, D., and Santel, F.: Digitale Nahbereichs-photogrammetrie zur Erstellung von Oberflächenmodellen für Bodenerosionsversuche. Publikationen der Deutschen Gesellschaft für Photogrammetrie und Fernerkundung, 9, 2001.

Wiggenhagen, M. and Raguse, K.: Entwicklung von Kenngrößen zur Qualitätsbeurteilung optischer Prozessketten, PFG, 2, 125134, 2003.

Woesten, J.: Soil Quality for Crop Production and Ecosystem Health. Development in Soil Science, chap. Pedotransfer functions to evaluate soil quality, Elsevier, The Netherlands, 221245, 1997.

Zeiger, M.: Assessment of dynamic biotic and abiotic processes at the soil surface affected by different management systems, Kiel, Germany, 185 pp., 2007. 